\title{
La Fuerza del Ombligo, Pedagogía de la Vida
}

\author{
The Navel Force, Pedagogy of Life
}

Isadora Cruz ${ }^{1}$

\section{Resumen}

El Cultivo y Crianza de Sabidurías y Conocimientos la "Fuerza del Ombligo, Pedagogía de la Vida", es un estudio que fluye y se entreteje como parte importante del camino recorrido por los pueblos originarios en Colombia revitalizados con la sabiduría que les otorga la Uma Kiwe (Madre Tierra) y el cosmos. Reflexiona en torno al mundo de los conocimientos, asegurando que con la occidentalidad estos quedan limitados a la escuela, mientras, en los pueblos originarios, se potencian en la tierra y en el territorio. Es un estudio que brota desde el relato, "la conversa" y los espacios de encuentros originados en las asambleas y las reuniones familiares con mayoras, mayores, sabedoras y sabedores, recuperando desde esta sabiduría la práctica de la comunicación que ha guiado el camino de la comunidad para defender el territorio, la identidad y la pervivencia del Pueblo Nasa. La riqueza del estudio trasciende las rupturas profundas y el dolor provocado por el conflicto armado colombiano y se centra en los desafíos presentes que tiene el Pueblo Nasa, por conservar sus raíces, prácticas, tradiciones, conocimientos, identidad, permanencia y lengua materna, la Nasa Yuwe. Cuentan los mayores que gracias a la lengua se lograron avances en la recuperación de la tierra. Con esta importancia, el documento intenta cultivar ese saber que también brota desde el vientre de la Uma Kiwe (guiador espiritual).

Palabras clave: fuerza del ombligo; pedagogía de la vida; pueblo nasa; nasa yuwe; uma kiwe.

\section{Abstract}

The Cultivation and Breeding of Wisdoms and Knowledge the "Navel Force, Pedagogy of Life", is a study that flows and interweaves as an important part of the path traveled by the original peoples in Colombia revitalized with the wisdom granted by the Uma Kiwe (Mother Earth) and the cosmos. Reflect on the world of knowledge, ensuring that with the western world these are limited to the school, while, in the original peoples, they are empowered in the land and in the territory. It is a study that springs from the story, "the conversation" and meeting spaces originated in assemblies and family gatherings with elderlies, knowledgeable people, recovering from this wisdom the communication practice that has guided the path of the community to defend the

1 Master en Comunicación Intercultural con Enfoque en Género. Email: laflacapayumat@yahoo.es

Recibido: 26/02/2018 Aprobado: 28/o8/2018

Cruz, I. (2018). La Fuerza del Ombligo, Pedagogía de la Vida. Ciencia E Interculturalidad, 23(2), 174-192. D0I: https://doi.org/10.5377/rci. v23i2.6576 
territory, identity and survival of the Nasa People. The richness of the study transcends the deep ruptures and pain caused by the Colombian armed conflict and focuses on the present challenges that Nasa People have, to conserve their roots, practices, traditions, knowledge, identity, permanence and mother tongue, the Nasa Yuwe, the older people tell that thanks to the language, progress was made in the recovery of the land. With this importance, the document tries to cultivate that wisdom also springs from the belly of Uma Kiwe (spiritual guider).

Keywords: navel force; pedagogy of life; nasa people; nasa yuwe; uma kiwe.

\section{Introducción}

Nuestros pueblos originarios han recorrido un largo camino acompañados de conocimientos que les ha brindado la naturaleza. Sus pedagogías ancestrales les han permitido vivir en conexión constante con la Tierra y con el Cosmos, hasta llegar al punto de entender a la Tierra y sentir amor por ella.

Para el mundo occidental los conocimientos siempre van a estar concentrados en la escuela, pero para la mayoría de los pueblos originarios los saberes están en la Tierra, esa Tierra que durante miles de años les ha dado el alimento físico, espiritual y en conocimientos para seguir perviviendo en el tiempo como pueblos.

Aunque el escrito arranca con el contexto y el sitio donde está ubicado el Pueblo Nasa, (lo cual hago para ubicar al lector), es un texto que aprovecha el relato de la vida de Isadora (persona quien escribe el texto) cuando era niña, para sumergir la palabra y expresar el pensamiento y la rebeldía de un pueblo que en cada etapa de su existencia le ha tocado enfrentar los desafíos que irrumpen la vida de su territorio, impuestos por el mundo blanco.

El contenido del texto se centra en la pedagogía desde el vientre de la madre, enseñanzas que van relacionadas con el ombligo de la Tierra (lugar donde se origina la semilla). De ahí la frase "el Nasa es mitad persona y mitad naturaleza"; en ese sentido, hablo de la siembra de la semilla ${ }^{2}$ desde el ser nasa, recogiendo los cuidados físicos y espirituales que deben realizarse a la semilla para que no se gorgojee (no se dañe por dentro como una semilla a la que le entra un insecto llamado gorgojo) en la vida. Además, la necesidad de tener en cuenta el camino de la Luna para sembrar la semilla. Así mismo, muestra de qué manera la mamá y el papá enseñan a sus hijos desde pequeños las tradiciones nasa desde el hogar.

2 Desde el pensamiento nasa, la semilla es desde donde se orina y se multiplica la vida. Por ello, sembrar la semilla es el acto sexual, para establecer compromiso para procrear y reproducir más seres. 
La sabiduría puesta en estas letras son las palabras dulces y convividas con sabedores y sabedoras de nuestras comunidades, ya que sus conocimientos son el remedio para hacer posible la vida del ser nasa con corazón sano.

\section{El encuentro con mis raíces}

Los Nasas somos fruto del enamoramiento de Uma y Tay ${ }^{3}$, nuestros primeros padres que tejieron la vida. Nuestros dioses son la luna, el sol, la laguna, la montaña, el viento y la tierra.

Por eso decimos que las plantas y los animales son nuestra familia; con ellos convivimos cultivando la tierra y tejiendo nuestras artesanías. El conocimiento para nosotros es el sentir y el caminar, por eso intentamos que la sabiduría de nuestro pueblo camine desde el sentir del corazón. Saberes y sentires que brinda la naturaleza, pues la Tierra es madre y es desde allí, desde donde nace la vida; y la vida es semilla y para que ésta gemine hay que sembrar. El Nasa cuando siembra, planta sabiduría. Por eso la vida del Nasa brota de la Tierra, lugar donde está sembrado su ombligo.

Los Nasa tenemos sembrado el ombligo en distintos lugares de Colombia, en el continente Suramericano; mayoritariamente estamos sembrados en el departamento del Cauca, al sur del país, sobre la Cordillera Central.

$\mathrm{Al}$ igual que otros pueblos que existen en Colombia y en el mundo, los Nasas tenemos nuestra razón de ser, o sea nuestra identidad y cultura. Por eso contamos con nuestras plantas medicinales para curarnos de las enfermedades, nos armonizamos en medio de la montaña para aliviar el espíritu y si nos sentimos cansados o tristes brindamos a los espíritus mayores para estar armonizados y contentos, así nos fluyen las energías y ordenamos las ideas para seguir el camino.

Nuestra comunicación se da a través de las señas en el cuerpo y en los cantos de los pájaros; también escuchamos a nuestro gran padre, el Trueno. Así mismo, danzamos a la Tulpa (uno de los lugares de ceremonias) para agradecer al fuego, al viento y a la tierra. La Luna y el Sol nos dicen en qué tiempo hay que despertar las semillas para sembrar, o sea, miramos el Cosmos para tomar decisiones. Estas y muchas otras creencias son las que tiene el Pueblo Nasa, para hacer las cosas que le permiten vivir como personas cuidando y defendiendo los cerros, el agua, los animales, la tierra y los espíritus. Es por eso que el conocimiento para nosotros es el sentir, es el caminar con todo, ya que estamos en conexión con el Cosmos y con la Tierra, somos síntesis de la Tierra y el Cosmos.

\footnotetext{
3 En la lengua originaria del Pueblo Nasa, significa Madre, Uma, y Padre, Tay: padres constructores de la vida. "La mujer hablo y dijo: mi nombre es Uma y soy la mujer que teje la vida, el hombre a su vez dijo: yo soy Tay el hombre que construye la vida". Tomado del mito de Origen del pueblo Nasa.
} 
Sentimos los mismos problemas que tienen los pueblos del mundo, pues la Tierra es una sola y lo que pasa en otros lugares se siente hasta aquí. Milenariamente, nuestro pueblo ha vivido el genocidio y hoy vive una guerra de fusiles por la disputa del poder. Así también, ha sido testigo de una guerra silenciosa basada en la negación de nuestros saberes originarios, la Iglesia nos hizo bajar la cabeza, pero no para mirar la tierra, sino para que nos doblegáramos a sus creencias; se nos irrespeta nuestros derechos, somos vistos como folclor y como piezas arqueológicas que sirven para vender la cultura afuera. Se nos niega el poder vivir dignamente y nos maltratan nuestra Uma Kiwe. Hoy nuestros territorios están forrados de los monocultivos de caña por la industria, así como también son pretendidos por la minería; por defender a nuestra Madre Tierra nuestras comunidades han sido atropelladas por grupos armados al margen de la ley, por la fuerza del gobierno, por las multinacionales y hasta por las mismas leyes que implanta este Estado neoliberal.

En medio de este desafío camina un territorio llamado Huellas, y es aquí donde se encuentra mi comunidad, Carpintero, aquí germiné, aquí sembré mis semillas (hijos), aquí acompañó a mis semillas y a mi comunidad y es desde aquí desde donde escribo.

Aquí vivo arropada de tres cerros verdes que se imponen en mi comunidad. Dos ríos bordean a Carpintero y una quebrada la humedece dando vida a todo lo que encuentra a su paso.

Esa agua, ese ser líquido que hoy sigue dando vida a la vida, es el que mi madre cultivó junto a mí durante 9 meses, pues cuando la Luna caminaba alrededor de la Tierra, la barriga de mi madre crecía y tomaba forma circular. Allí, en medio de ese mundo oscuro, silencioso y cálido, crecieron mis articulaciones, mis sentidos y mis saberes, hasta que un día la Luna orientó mi germinación. Nací en Luna Silenciosa y en tiempo de invierno, o sea que tengo espíritu de lluvia intensa y por ello tanto llanto en mis ojos.

Dicen mis padres que aquí está sembrado mi ombligo, en el centro y debajo de las tulpas (piedras del fogón) de la cocina de mi casa. Pues esa placenta que plantaron en el fogón fue la pedagoga mientras yo crecía en la barriga de mi madre, por ella entró todo lo que a mi madre le sucedía en el entorno. Ahora entiendo mis miedos.

La siembra de mi cordón umbilical me conectó con la Tierra; este ritual impidió que me enfermara en la vida y me abrió el camino para juntarme al calor de muchas personas y me llevó a sentir amor por la Tierra, por mi familia y por mi comunidad.

Mis padres, como buenos indígenas Nasa, me abrigaron en una casa de barro al calor del fogón, al lado de cuatro hermanas y un hermano. La conexión con la Tierra, me permitió aprender desde niña de las bondades de la naturaleza. Aprendí a respetar y a cuidar el agua, la montaña, los animales, los árboles, las plantas medicinales, 
las aves y hasta el aire puro que me ofrecen los altos cerros que se imponen en mi comunidad. Aquí, de la mano de mi mamá y una tía, aprendí los oficios de la casa, a cultivar la tierra, a trabajar en minga y a tejer jigra.

En este bello lugar, en medio de la montaña, donde solo se veía nacer y ocultar el sol tras la cordillera, aprendí a escuchar e interpretar el sonido de la naturaleza, aquí mis padres me enseñaron la sencillez de la vida y el sentido por vivir.

Aquí en esta tierra, empecé a caminar la lucha de mis abuelos. Pues mis ancestros pisaron el polvo colorado, cargado de historia, de rebeldía pero también de esperanza. Ese camino dibujado de sencillez, felicidad, lucha, rebeldía y esperanza, fue lo que mis padres me sembraron en el corazón desde que estaba en la barriga.

"El campo es un paraíso" me decía mi padre cuando apenas era una niña, pero yo poco entendía; porque mi realidad, por momentos, no era ese paraíso del que mi papá me hablaba, pues por tiempos los vientos de la guerra tocaban la puerta de mi comunidad. Es tanto así que aún recuerdo los asesinatos de mis vecinos comuneros.

Pero a pesar de esto siempre guardé la esperanza que otro sol florecería mañana con más fuerza tras la cordillera y que ese brillo del sol sería el mejor regalo de mi vida para mi adolescencia y fue así cuando llegó el regalo de una larga lucha: el Estado colombiano reconoce a mi pueblo como ciudadanos de Colombia, otorgando derechos constitucionales por ser indígenas.

La alegría invade mi pueblo y la lucha continúa con más fuerza, pero la sonrisa en este territorio no duró mucho, justo ese mismo año de la nueva Constitución, el Estado colombiano masacra a 20 compañeros indígenas de este territorio, mientras se encontraban recuperando la finca El Nilo. Ese día pareciera que el sol que brilló ese año tras la montaña se había vuelto a apagar y ahora mi pueblo solo estaba reconocido en las letras que llenaban las páginas del libro de la Constitución, pues la realidad de mi territorio era otra, se había violado uno de los derechos fundamentales: la vida de un pueblo.

Aunque en mis oídos retumban las noticias de este acto de barbarie, poco entendía lo que estaba pasando, para mí eran solo unos asesinatos más.

El tiempo pasaba y los pasos de mi pueblo se juntaban con otros y otras, para hacer más fuerte la lucha. La movilización y las asambleas eran el camino. Mi pueblo se organizó en asociación y en plan de vida. Mi territorio había crecido y continuaba el sueño de la lucha por la autonomía, mis padres eran testigos de esa organización política. 
En medio de las realidades que vivía mi territorio llegué a la adultez, mis padres, mi familia y mi comunidad seguían dedicados a sembrar comida al servicio de lo colectivo pues su política era cultivar, cuidar y defender la tierra.

"El camino no ha sido fácil, aquí hay muchos intereses desde el Estado y no podemos dejarnos llevar por lo que dice un bando u otro, nuestra política siempre debe ser cultivar la tierra. Los que están en el poder siempre van a querernos engañar, pareciera a veces que los derechos constitucionales ganados por la lucha fueran una trampa; pues la Constitución nos reconoció, pero era para que los indígenas dejáramos de recuperar las tierras de los ricos y para que dependiéramos del dinero que nos devuelve el Estado en transferencias, por eso es que la lucha nunca se acaba, primero se acaba uno" me explicaba mi papá.

Este consejo que añade mi padre, lo reafirma el himno de nuestro pueblo Nasa, convertido en poesía, "Seguiremos luchando mientras no se apague el Sol", esa es la frase que más me gusta, pues eso es lo que veo que pasa todo los días aquí en mi territorio, aquí la gente no se cansa de la lucha y en medio de la tristeza le sonríe a la vida.

Es tanto así que en esta tierra todos los 16 de diciembre se conmemora la masacre de El Nilo, memoria que se hace en un territorio estratégico para los grupos armados, para el ejército colombiano y para el mercado mundial; aquí 160 hectáreas de caña invaden este pueblo originario que se niega a ser exterminado por el sistema capitalista.

Aún así mi pueblo camina a un desafío que emprendieron los mayores y mayoras históricamente, la 'liberación de la madre Tierra'. Los liberadores dicen: "no estamos luchando con un terrateniente como en los años 70, estamos luchando con el latifundio que no deja que nuestra madre sea libre. Aquí llego la minería, nuestro río se enojó y ya profundizó el agua, los dueños de los cultivos de arroz y de la caña se pelean la poca agua que queda", ratifica un liberador.

Hoy mis padres continúan cultivando la tierra y viviendo en comunidad, veo en sus ojos, en sus cabellos, en sus rostros y en sus manos la profesión que siempre han tenido, la esperanza.

Mientras, yo camino acompañada de los consejos de ellos, en medio de la lucha de mi comunidad, de mi territorio y de mi familia; pues desde aquí intento hacer una educación desde el sentir en el corazón y una comunicación distinta que nos enraíce con la tierra y con nuestra historia, una comunicación que resalte lo bello que tiene mi pueblo, su sabiduría y el conocimiento que han guardado en el corazón los mayores y mayoras durante años; pues creo que si tenemos nuestra identidad bien fundamentada en el corazón, en la vivencia y en el sentir, podemos dar el siguiente paso como pueblo. 
Pedagogía Nasa, enseñanza para sanar el corazón y la Tierra

Para el Pueblo Nasa la pedagogía es enraizar en sus hijos e hijas los principios del respeto y la reciprocidad por y con la Tierra, elementos fundamentales que permiten arraigar al nasa a la raíz y al sentir de la Madre Tierra. Por eso se debe hacer todas las prácticas que se requieren para la maduración del cuerpo del niño o la niña, en la parte espiritual, física y de conocimientos.

El Pueblo Nasa no habla de habilidades, destrezas y aptitudes; habla de dones, poderes y saberes; la transmisión de dones y saberes en el nasa, se inicia desde el vientre materno, a través del cual, la madre, el padre, la familia, la partera y el kiwe thë le transmiten sus costumbres y su cultura a través de los diferentes rituales en cada ciclo de la vida del nasa. Aquí es importante la lengua nasa yuwe (lengua originaria del pueblo Nasa); ya que desde este momento se va generando la apropiación de la identidad cultural y de los roles en los hijos e hijas.

Este proceso de transición de saberes se afianza con la ritualidad, pues las prácticas espirituales en el niño y en la niña Nasa se hacen de acuerdo a lo que oriente la naturaleza y el kiwe thë. Cuidados que se deben hacer para madurar el cuerpo del niño y de la niña. Estas instrucciones se empiezan a realizar desde el vientre, pasando por la niñez, cruzando la etapa de enamoramiento hasta llegar a la conformación de la familian, o sea, su adultez. También en estos ciclos de vida del ser nasa, cumplen un papel fundamental los padres y el territorio donde conviven.

Además, en el espacio familiar de la cotidianidad de la vida, los niños aprenden a través de la observación, la imitación y el ejemplo que brindan las mayoras y mayores sabios, así las niñas y los niños van asumiendo sus oficios y definiendo su vocación.

También en este procesosiguen jugando un papel importante los diferentes miembros de la familia, abuelos, hermanos, hermanas, tíos y tías, ya que de esta relación se desprende el reconocimiento e importancia de los familiares y el afianzamiento de los valores y pautas culturales nasas.

Es por eso que los saberes y los oficios de la mujer nasa se aprendían principalmente al lado de la mamá. El papá, las abuelas, los abuelos y la comunidad enseñaban a las niñas y a los niños a crecer dentro de la familia y a convivir en comunidad, pues ellos debían brindar el ambiente necesario para permanecer en familia y en el proceso comunitario. 


\section{Maduración de la semilla}

La vida de la niña nasa transcurría al lado de la mamá entre aprender los oficios de la casa y tejer. Cuando la niña empieza a tejer la primera mochila o jigra, significa que ha iniciado con la maduración del conocimiento de ser mujer nasa.

La primera mochila que la niña nasa tejía casi siempre quedaba con imperfecciones, por eso debía emprender otra para corregirlas. En esta etapa la niña pasaba de U'sxa a Üusskwe jxpsa, es decir, persona que empieza a tener conciencia de su ser nasa.

Cuando la niña ya tejía las dos mochilas demostraba que U'sxa iba muy bien en el proceso de aprendizaje y conocimiento de su labor y de responsabilidad frente a la vida.

Para reforzar este conocimiento la mamá tomaba el par de mochilas en la mano derecha y con ella rodeaba el cuerpo de la niña formando un espiral, mientras decía: "ya eres una mujer, tienes que seguir tejiendo para que luzcas con tu marido. Guardemos este par de mochilas para que tus energías siempre te acompañen. No las puedes, vender porque tu saber se irá en las manos del comprador".

La niña entre más mochilas tejía demostraba más capacidad en sus conocimientos. Cuando ya tejía cuatro mochilas se caracterizaba por desarrollar bien su creatividad en la combinación de colores, figuras y en los diversos tamaños del tejido. Este tiempo venía acompañado de conocimientos en el saber cocinar y cultivar en el tul (huerta), además ya sabía relacionarse con educación con las demás personas de la comunidad.

Cuando la niña terminaba de tejer tres pares de mochilas era un gran acontecimiento para los padres, ya que con esto la joven nasa demostraba que había profundizado sus conocimientos. Es aquí cuando sus padres le permitían tener novio puesto que se consideraban que estaba preparada en responsabilidades individuales y comunitarias. Si no terminaba los tres pares de mochila se le consideraba una mujer perezosa y novata así fuera grande en edad.

Por ello era necesario que la mujer nasa aprendiera a tejer los tres pares de jigra y un par de chumbes, así como también debía saber cocinar y cuidar el tul, saber solucionar problemas y aconsejar, entender y practicar el camino de la luna y además saber la lengua. Estos saberes la situaban como una mujer jecha (mujer sabia y, lista para conformar una familia) y ya podía conseguir marido. En este periodo a la mujer nasa se le llamaba knasa, señorita, ya que tiene los conocimientos necesarios y su cuerpo está preparado para procrear y conformar una nueva familia; por eso se le decía U'ynxa’ja' "ya es mujer". 
Aquí comienza con su primera menstruación, durante este tiempo debía permanecer en la casa, no bebía visitar el tul y no debía sembrar ninguna planta. Tampoco debía visitar los sitios sagrados (montaña, ríos, ojos de agua entre otros), no debía comer lácteos ni frutas ácidas. Además, no podía bañarse en campo abierto, debía bañarse con agua de plantas calientes y en un solo lugar, debía sembrar el agua que utilizó durante el baño ya que por primera vez la señorita está expulsando energías espirituales fuertes; aquí era necesario que una persona mayor o su mamá le enseñara los cuidados que se debe tener, ya que de lo contrario podía causar desequilibrios en la familia o en el entorno. Por eso desde la concepción nasa la mujer es más fuertes en la energía espiritual que el hombre, porque ella coordina su cuerpo con el camino de la luna y en cada ciclo de la luna la mujer cambia la energía de su cuerpo.

Entre tanto, la vida del niño nasa, durante sus primeros años, transcurría al lado de su mamá. En la espalda de su madre iba al tul, allí observaba como su padre sembraba y cortaba las plantas; miraba de qué manera cargar la leña y el revuelto, echaba de ver como su mamá prendía la candela y se ocupaba de la cocina. Cuando ya era más grandecito acompañaba su padre a la parcela, recolectaba el agua y ayudaba a traer la leña para que su mamá atizara el fogón. También empezaba el aprendizaje de trenzar la cinta para tejer el Cxwá, sombrero, y las sandalias, pelkatx.

Sus conocimientos iban creciendo y durante esta época el niño salía con su papá con más frecuencia, o con el abuelo, a trabajar en el tul o en la parcela de sus familiares. Así mismo acompañaba en las mingas familiares y comunitarias, aquí obtenía más conocimientos sobre el trabajo en el campo, aprendía a construir cercas, puentes, caminos, canales de agua entre otros y a cultivar la tierra.

En estos tiempos aprendía a interpretar canciones que escuchaba y a fabricar sus propios instrumentos musicales y sus juguetes.

A la edad de los 13 años iniciaba con el cultivo de su primer maizal. Con ello, el joven nasa demostraba su gran capacidad para el trabajo, el cual lo hacía de acuerdo al ciclo lunar; saber el camino de la luna le permitía saber cuándo debía sembrar para cuidar el cultivo de los insectos y para tener una buena cosecha; así también miraba la luna para saber en qué tiempo debía cortar la madera para construir las cercas para proteger los cultivos. Con la construcción de la roza de maíz demostraba que estaba preparado para formar una familia. En este periodo al hombre nasa se le llama picthe, hombre que sabe. Si el joven no lograba terminar su cultivo se le considera perezoso y tenía pocas posibilidad de conseguir una compañera, ya que para poder conformar una familia o conseguir compañera, el hombre nasa debía saber hacer sombreros, haber terminado dos maizales grandes o haber hecho una parcela, pero si no la tiene es perezoso e irresponsable y "mantendrá su familia con hambre debajo de una piedra". 
Con estos saberes venía la etapa del enamoramiento; periodo importante para la vida nasa ya que desde este momento se empieza abonar el terreno para sembrar la semilla o dicho en otras palabras, se empezaba a cuidar al hombre y la mujer espiritualmente y físicamente para procrear un nuevo ser. Dicen los sabios y las sabias que desde aquí comenzaba el sueño de la semilla del hombre y la mujer nasa y para eso debía hacer una buena selección. Por eso era necesario realizar el cateo con el kiwe thê, para que analizar si las energías del hombre y la mujer eran compatibles o de lo contrario podía haber problemas en esta etapa.

Si era posible esta unión, venía el periodo del amaño lo que en el mundo occidental le llaman el noviazgo; aquí se realizaba el ritual del amaño, se hacía para preparar a la mujer y al hombre para que estuvieran listos para conformar la familia. Unión que también se hacía desde lo espiritual, es decir que con los cuidados espirituales y físicos los jóvenes podían lograr un hogar responsable y duradero. Se dice que si desde la etapa del enamoramiento se maneja la ritualidad, se formará una familia de corazón nasa. Ya que la familia es entendida desde la ley de origen como el nuevo amanecer de otra vida, o, también, como sembrar una semilla de maíz, si la semilla está sobre buena tierra, dará buena cosecha.

Los Nasas no hablaban de pareja, sino de familia; en la familia estaban abuelos, nueras, tíos, sobrinos y padrinos. También hacían parte de la familia los animales, las plantas y los minerales con los cuales se relacionaban, por eso hablaban de una familia extensa.

La familia en el Nasa es portadora de semilla, por lo tanto la familia nasa es la que garantiza la continuidad de la vida del ser nasa, pero no solo por sembrar la semilla, sino también por fecundar saberes de su pueblo.

\section{Siembra de la semilla}

El embarazo en el Pueblo Nasa es el acto de sembrar semilla, es el acto de sembrar un nuevo ser, por eso cuando un hombre y una mujer hacen su relación sexual es entendido como la siembra de la semilla, desde allí,parte la vida del ser nasa. Se hace necesario que para sembrar la semilla se escuche los consejos de la Luna si se quiere concebir un niño o una niña y además para que germinen o nazcan bien fuertes. En este ciclo de vida de la semilla, nuestros guiadores espirituales y nuestras parteras junto a la familia de embarazados, realizan los rituales, prácticas pedagógicas ancestrales, que se hacen para trasferir o heredar las fuerzas y las energías de la Tierra, así como para despertar los dones en las semillas desde el vientre de la madre. Esto se hace para empezar a madurar la semilla y para que no le caiga gorgojo, podríamos decir que aquí se continúa guiando el camino de la vida del niño y la niña; para ello, en esta etapa del embarazo, son fundamentales los rituales, los cuidados y las prohibiciones que aconseja el kiwe thê y la partera a la familia de embarazados. 
Además, para sembrar la semilla se debe tener en cuenta las orientaciones del camino de la Luna, ella es la que indica en qué tiempo se debe sembrar la semilla, dependiendo qué semilla quiero cosechar, hembra o macho. Dicho en otras palabras, si la familia quiere un hombre o una mujer se debe sembrar en lunas distintas. Por eso, cuando los mayores soñaban con sus semillas siempre tenían en cuenta el camino del Sol y la Luna, por ello sus semillas fueron par, nunca sus semillas fueron de un solo sexo ya que todo era concebido desde la cosmovisión.

En la familia nasa siempre las semillas deben ser par, hombre y mujer, hembra y macho. Así también es concebida la semilla de las plantas. Allí hay macho y hembra, en los animales también hay par y esto hace parte de la vida del ser humano.

Se recomienda que para sembrar la semilla se debe hacer en luna mayora o sabia, luna llena, para que la semilla sea fuerte, pensadora y muy trabajadora. Además, para tener pocas complicaciones en el embarazo. De la misma manera, se debe tener en cuenta los consejos del padre Sol ya que, dependiendo de la época, él nos regala sus energías. Cuando una semilla germina en época de sol grande o en verano, pues estas personas suelen ser muy alegres. Pero si la semilla fue en otra luna, puede ser que tenga problemas en el embarazo y afecte el desarrollo de la semilla; entonces aquí hay que hacer toda una práctica cultural para evitar ciertos riesgos. Si el niño se siembra en luna nueva, cuando nazca el niño hay que hacer un ritual en luna llena para potencializar la semilla, así coge fuerzas y no será débil o con enfermedades.

La semilla ya sembrada empieza a germinar y madurar en un espacio de la "mochila", que es el útero de la mujer. Pues en el Pueblo Nasa se guardan las semillas en una mochila para mantener siempre la vida y las semillas son sinónimo de vida y la mochila es el tejido que representa los pasos de la creación de la vida, por eso se asemeja con el vientre de la mujer. Ese es el primer espacio donde comienza a crecer la semilla. En nasa yuwe se dice dü yaja, mochila de parir.

Una mochila se empieza a tejer en espiral o en caracol, como me dice mi mamá. Desde que empieza la construcción de la mochila y hasta que termina, la conforman los hilos, los nudos y los huecos. Aquí está el camino del nasa: los hilos que significan la construcción del camino de la vida, los hilos hacen vibrar dependiendo de la fuerza que heredó la semilla desde el vientre; los nudos, que significan cada paso del niño y de la niña; y los huecos o los vacíos son los que representan los problemas que van apareciendo en cada paso, lo cual deberá reflexionar y volver atrás y repasar su vida, para sortear sus pasos y seguir el camino.

La vida del ser nasa se mueve en un espiral desde que comienza la sembrada de la semilla, pues el primer espiral que caminamos es la unión del agua con el espermatozoide y la semilla de la mujer, o sea que podríamos decir que nosotros somos del mundo en espiral por naturaleza. También podríamos decir que el espiral es la fuerza 
de los ancestros y de la Tierra, ya que todo lo que interpreta el kiwe thê gira desde el conocimiento que le ha dado la Tierra.

Para seguir entendiendo la siembra de la semilla debemos que tener en cuenta la siembra como el acto sexual, la fecundación como la unión del espermatozoide, el nacimiento como la germinación, el crecimiento como la maduración, la cosecha como la conformación de la familia y la trasformación como las personas mayoras, sabias que aconsejan, estos ya son los abuelos. Aunque se dice que algunas personas nasas no logran cumplir todas estas etapas y llegan al último periodo siendo necias, personas sin sabiduría.

La función de la familia nasa es proteger, cuidar y guiar a la semilla para mantener la armonía. Dice un mayor "como nasa tengo que reproducirme, tengo que procrear, pero también debo cuidar la semilla que está entorno a mí, debo mantener la especie en relación con los otros seres. Si la familia se destruye, morirá el Nasa".

Por eso, cuando la nueva familia se embaraza, se espera que la vida de la mujer transcurra normalmente ya que significa vida, pervivencia y semilla que está en el vientre. El embarazo y la maternidad nasa son vividos como un evento natural, que alegra a la familia y a la comunidad, es el don de transmitir la vida, pues la mujer ha sido delegada por la madre naturaleza para generar vida y por ello la han dotado de todos los elementos necesarios para cumplir a cabalidad con tan preciada misión.

"El Cuidado de la mujer en el embarazo empieza desde niña, con el primer periodo menstrual, ya que se debe tener cuidado, porque desde allí comienza la fertilidad. Hay cosas de éstas que no hemos hecho y por eso tenemos complicaciones en el embarazo. Cuando una mujer queda en embarazo, el kiwe thë sabe con qué espíritu va a nacer el niño y es allí donde hay que ir armonizando, porque es aquí donde se define como va ser su actitud y el comportamiento ante la familia y la sociedad; estas son las cosas que se deben ir armonizando, para ir equilibrando", asegura la mayora Bertha Rivera.

Por eso desde ese momento se debía realizar las prácticas culturales para proyectar la vida de la semilla; en tiempos pasados las mujeres nasa, cuando se embarazaban, debían poner cuidado a los espíritus de la naturaleza, para que el embarazo caminara bien. Se debía respetar las normas culturales que las encaminaban a la armonía. Por ejemplo, no podían visitar los ojos de agua después del atardecer. Tampoco debía salir en los días de eclipses, en las lluvias del arco y en los cambio de luna.

De igual manera, en esta etapa, las parteras recomendaban hacer la primera consulta con ellas. Pues era necesario realizar el control con la partera desde el comienzo del embarazo, así la partera las acompañaba durante todo el proceso; se hacían 'arreglar el estómago' cada dos meses o cuando sentían molestias, de esta manera se iba 
aflojando el cuerpo, y se iban preparando para el momento del parto. Si era primeriza, debía visitar la partera con más frecuencia.

Junto a la partera, era necesario visitar al kiwe thë para que realizara el ritual de armonización. Ya que el ser que está en el vientre es una persona muy limpia, pues en el embarazo no solo el arco molesta, sino también otros espíritus que miran al niño para apoderarse. En este tiempo los puede perseguir el espíritu de la chuma, el ratón y de la ardilla. Y si no se hace la armonización a tiempo, los espíritus de estos animales se apoderan de la criatura y cuando nazcan ellos empiezan actuar muy bravos y rebeldes, además presentan enfermedades y en su etapa de crecimiento cogen malos vicios.

También, para evitar otros malestares en la mujer, se aconsejaba usar ropa floja, que le permitiera andar cómoda, tanto a la mamá, como a la criatura que estaba en la barriga. La mujer nasa acostumbraba a continuar con los oficios de la casa y en el tul, pero se recomendaba hacerlo con cuidado y descansando para evitar la fatiga.

Cuando la partera sobaba y arreglaba la barriga a la embarazada, se tejía una gran confianza entre la criatura que estaba en el vientre, la mamá y la partera. La familiaridad que había entre las tres personas hacía que la mamá se sintiera bien y pudiera contarle a la partera con confianza lo que sintiera en su vientre. Ya que la partera era una ayuda fundamental para la embarazada, porque era quien sabía aliviar las molestias durante el embarazo, el parto y la dieta.

Con las plantas medicinales la partera iba preparando a la mujer para el parto. Además era necesarios que las embarazadas visitaran el kiwe thë, con esto se lograba la corrección de los riesgos a tiempo. El kiwe thë hacía el primer ritual de armonización, que se realizaba en relación con la Madre Tierra, pues se debía hacer en los tres primeros meses de embarazo, así sucesivamente hacía tres o cuatro rituales, o los que el kiwe thë considerara conveniente, hasta que naciera la semilla.

También se regaba la planta y la semilla, mejor dicho, hablemos de los baños con plantas medicinales durante el embarazo de la mujer nasa. Los baños se hacían con hierbas calientes, recomendados siempre por la partera ya que la mayoría de las veces se hacían para calmar los dolores del cuerpo y para sacar el frío del vientre. Si el baño era de remedio, se hacía con aguas calientes, pero se recomendaba hacerlo en un sitio sin corrientes de aire para que la embarazada no se hinchara.

También, cuando ya se tenía cierto tiempo de estado de embarazo, había que proteger al niño porque hay espíritus como el arco (acompaña y espía a las mujeres, pero también castiga la desobediencia) que están mirando a la criatura que se va gestando, entonces hay que protegerse fajándose con un chumbe, porque si no se faja el vientre con el chumbe, el arco molesta a la criatura por eso hay que utilizar el chumbe como forma de protección. Este chumbe debía tener los siete colores que 
tiene del arco (iris) para una mejor protección ya que si la mujer estaba chumbada, el arco la miraba y ya no le hacía ningún daño. Pues el chumbe representaba energía y protección para la mujer.

Son los kiwe thë y las parteras quienes guiaban cuántos meses de embarazo se debía fajar con el chumbe ya que este ayudaba a calentar el vientre de la madre y evitaba que cogiera frío el estómago; pero ellos no solo fajaban con el chumbe, si había problemas de que el niño se quisiera venir antes de tiempo, hacían fajar a la mujer con plantas de bejuco de la batata para evitar este riesgo.

Si la embarazada presentaba otras molestias era necesario consultarle a la partera, quien podía recomendarle baños especiales con plantas medicinales (por ejemplo, los baños de asiento). Así mismo la partera aconsejaba realizarse el aseo diario recibiendo el sol.

De igual manera, durante el embarazo se empezaba a tejer la historia desde el vientre a través de las relaciones familiares que eran muy necesarias en la espera de un nuevo ser.

La embarazada necesitaba tranquilidad en el hogar. Ella aprovechaba el descanso para hilar o tejer jigras, chumbe y para preparar la ropa y todo lo que era necesario para la semilla. El chumbe era de mucha utilidad durante y después del embarazo. También era muy significativo para la naturaleza, por eso la partera aconsejaba a la mujer que estaba en embarazo empezar a tejer el chumbe con los colores del arco iris, ya que si no lo tejía debía comprarlo. Sus tejidos estaban acompañados de silbidos o cantadas, además en su tejido iba hilando su historia y la de su pueblo.

La embarazada debía hablarle al nuevo ser en su lengua materna, pues desde el vientre de la madre el ser nasa empieza a escuchar, aprender y a obedecer la parte espiritual. También la familia, tímidamente, iba conversando con la criatura que estaba en el vientre, para que fuese un niño alegre con su familia y la comunidad. La embarazada debía descansar y dormir bien. Por ello había que mantener en la familia un ambiente de comprensión, diálogo y solidaridad para compartir con el nuevo ser una vida con alegría. Se aconsejaba siempre que todos debían brindarle mucho afecto a la embarazada y a la criatura que estaba en el vientre ya que ambos lo necesitaban.

Era necesario que las embarazadas escucharan consejos o las experiencias de vida de las mayoras de su comunidad, mayoras que ya hubieran tenido hijos, para lograr reforzar las prácticas culturales y los cuidados durante el embarazo, el parto y la dieta. Cuentan que en tiempos pasados no era muy común juntarse con otras embarazadas de la comunidad, pero dicen que cuando llegaron las promotoras de salud les aconsejaron juntarse para ayudar a tejer experiencias de unidad y solidaridad. 
Antes, la familia nasa tenia entre seis y doce hijos y todos nacían seguidamente. Después de los encuentros con las promotoras de salud se les orientó cuándo debían llegar nuevos hijos al hogar nasa. Entonces se dijo que para poder estar fuertes y recuperadas para otro embarazo, era mejor que ya el niño pequeño tuviera la edad de poder caminar solo. De esta manera, la familia podría recibir otro niño en el hogar. También la familia pedía consejo a un kiwe thë para ayudar a extender el el tiempo antes del nacimiento de otros nuevos seres en la familia.

El alimento de la semilla no solo era la comida de la mamá durante el embarazo, era también los rituales para despertar los dones en la semilla y para que ese nuevo ser creciera en sabiduría, todo esto para que la semilla no se gorgojeara en el camino de la vida. También era necesario cultivar la tierra. Por eso cuando la familia nasa esperaba un nuevo ser, debía trabajar unida en el tul, allí debía cultivar y lograr disfrutar de suficiente comida y de buena calidad. Pues la embarazada necesitaba alimentarse bien, con productos nativos y nutritivos, para que ella y su semilla estuvieran bien nutridos y fuertes. La partera recomendaba alimentarse bien comiendo fríjol cacha, zapallo, chaguasgua (agua de maíz), mote, caldo de huevo con ajo. Además el kiwe thë y la partera orientaban consumir plantas y alimentos calientes para sacar el frío de la matriz. Se aconsejaba no consumir alimentos irritantes (por ejemplo, carne de cerdo) tampoco debían consumir gaseosas, mecato, empaquetados o comida chatarra ya que esto debilitaría la vida de la semilla y podía traer frío al vientre.

Para la dieta era necesario tener lista la arracacha, el ajo, el plátano, la gallina de patio, el chocolate, la miel, los clavos y la canela. Los productos para la comida debían ser cultivados sin venenos ni químicos, debían provenir del tul, para estar seguros de que los alimentos que comía la familia y sobre todo la embarazada fueran de buena calidad.

\section{V. “Germinación de la semilla”}

Ahora es tiempo de que la semilla germine. El kiwe thë analizaba si el nuevo ser podía nacer en casa, el éxito del parto dependía de los cuidados que se ha habían tenido desde que la mujer era niña.

La familia, junto con la partera, preparaba con anticipación las cosas necesarias para la atención del parto en la casa. De la misma manera se alistaba el lugar, cubriéndolo con carpas para que no se filtrara el frío, la mayoría de las veces era el dormitorio, pues se necesitaba un lugar que brindara intimidad a la familia. También se aseaba el lugar donde iba a ser el parto. Si la madre llevó todos los rituales de armonización, una vez haya cumplido el ciclo de la Luna, la criatura busca el camino. Allí viene el procedimiento de la partera ya que es la encargada de preparar el camino del niño, ella arregla a la mujer. Si en este camino el niño se desubica, allá dentro, en su primera casa, la partera lo acomoda, a esto se le llama calentar el vientre; la partera arregla el 
vientre para abrir el camino, para que el niño busque la salida. Esto se hace faltando dos días, un día y a veces faltando horas para comenzar los dolores.

En este momento la familia le brindaba mucho apoyo a la mujer, mientras otras personas de la familia se dirigían a buscar la partera con rapidez para que todo saliera bien. Al llegar la partera, la tranquilizaba y le brindaba mucha confianza para darle valor a la madre.

Otros familiares soplaban el fogón para que brindara calor al hogar, también era allí donde se hervía el agua para preparar las bebidas de las plantas medicinales.

Los vecinos llegaban para brindar ayuda en lo que se necesitara; entonces se les pedía el favor de hacer una camilla de madera para movilizar a la madre si es que fuera necesario. También se buscaba un carro, porque la camilla era solo hasta la carretera y se invitaba a la comunidad para que fuera a ayudar a cargarla hasta donde estaba el carro.

En el momento del nacimiento las parteras y el kiwe thë observaban bien la naturaleza ya que el nacimiento de la semilla en el territorio tenía identidades que se relacionaban con los tiempos y espacios de vida, lo que permitía los cuidados desde las prácticas culturales, por eso desde el vientre ya eran familia con los otros seres del territorio. Pues cada niño nasa está orientado por las energías de los tiempos y la posición de la Luna y el Sol, esto permite que cada ser sea diferente al otro en la parte física, espiritual e intelectual.

Mientras tanto, la partera seguía con la madre sobando la barriga para arreglar el vientre, hasta ubicar al bebe en una buena posición. Para hacer este trabajo se apoya en las bondades de las plantas medicinales preparando remedios en infusiones o cremas, incluso con sustancias los animales para orientar, agilizar y facilitar el camino del nuevo ser (también para curar hemorragias en caso que se presente durante el embarazo).

Miraban la hora del nacimiento si es medio día, media noche o en las horas de la mañana; era también importante mirar si había visita del viento, lluvia, aves, sol y estrellas. Dicen los sabios que "si nace a medio día y está haciendo sol, el niño va a ser fuerte en la vida pero si nace en la mañana es débil y si nace en tiempos de lluvia va ser muy llorón".

"A la hora del parto la mujer se debe sostener de un chumbe y no debe haber mucha gente porque la criatura se pone celosa y no se viene rápido y hace sufrir a la mamá, y si en ese momento entra un niño o una niña al lugar donde la madre está dando a luz, es peor, él bebe no busca camino y se está quieto", explica la partera Libia corpus. 
Una vez el niño salga a la luz la partera con el kiwe thë identifica el destino del nuevo ser nasa, esto se hace de acuerdo a la lectura de la naturaleza y de acuerdo al sitio donde nace, pues cada sitio tiene espíritus diferentes, por eso recoge energías de los cultivos, la huerta y de los caminos. Cada uno de estos espacios tiene espíritus de trabajo y de recorrido por el territorio.

También los mayores interpretaban la forma del nacimiento de cada ser, pues cada bebé nace de diferentes maneras y con diferentes comportamientos: de pie y de cabeza, boca arriba y boca abajo; llorando, en silencio y con colores en la piel, pues estas son señales que tienen significado en la vida de los niños y las niñas nasa.

\section{Siembra del ombligo}

Después de su germinación viene la cortada del ombligo, este ritual es realizado por la partera o partero y se hacía con la hoja de caña o con una astilla de carrizo, ya que esta planta tiene relación con la naturaleza y cuando se siembra el ombligo lo terminan de amarrar a ese espacio natural. Si el cordón umbilical se corta con una tijera o con cualquier elemento metálico, dicen que desde este momento se empieza a enfriar el corazón de la semilla, entonces van entrando pensamientos fríos a su cabeza, puede pensar en matar a otra persona ya que el material de metal hace que los niños se vuelvan bruscos.

La partera o el médico tradicional continúan con su extraordinaria labor, ahora con la siembra del ombligo. Para ello los mayores recomendaban hacerlo en la tierra, para relacionar al niño con la Tierra, es como si se casaran con la Tierra; desde allí nace el apego a la Tierra, y el gusto por cultivarla. Esta siembra se hacía con plantas frescas y un poco de ceniza, dentro de la casa, en la cocina cerca del fogón o en el tul.

\section{Rituales de limpieza}

Así mismo, después de que nacía el niño o la niña se hacía la limpieza del sucio ${ }^{4}$ de la madre y del recién nacido con el kiwe thë; consistía en bañar al bebé con remedios para "chupar" el sucio antes de sacar el niño de la casa y así lo prevenía que se fuera a enfermar.

Con este ritual se sella el pacto y compromiso entre los espíritus mayores de la naturaleza, el recién nacido y los padres para dar apertura al camino de vida del nuevo ser nasa, por ende se busca que el nuevo ser pueda convivir en armonía y lleve la esencia, el pensamiento y los sentimientos como nasa; de igual forma fortalece el lazo

4 El sucio para los Nasas es el establecimiento de la relación sangre/muerte/espíritu. El arco es considerado el espíritu más limpio y este se enoja cuando no se limpia el sucio, lo que puede ocasionar enfermedad y muerte. 
de pertenencia al territorio para que en la adultez no abandone el territorio donde fue su nacimiento, ni los lazos familiares.

Al mes de su nacimiento debe realizarse un refrescamiento antes de sacarlo por primera vez de la casa, para que no tropiece con el sucio y no se enferme. Se acostumbra regalar un animalito, para potenciar su buena suerte.

Al tercer día se debe limpiar y lavar el sucio, para ello se hace un hueco al lado izquierdo de la casa, la mujer se baña con plantas calientes y con aquellas que le haya definido el kiwe thë, esta agua no debe caer a ninguna fuente de agua, si esto ocurre se hace el mal a toda la comunidad presentándose enfermedades, muertes, conflictos.

Después, la partera limpia la matriz y la arregla para que no le quedara dolor por las piezas de sangre que le podían quedar allá, y volvía a revisar la matriz en 15 días. Seguidamente la bañaba con plantas calientes, y así aliviaba y limpiaba el cuerpo y prevenía de espasmos a la madre; la partera recomendaba cumplir la dieta después del parto consumiendo alimentos calientes y no irritantes para lograr una buena recuperación y para que la mujer siguiera conservando la fuerza espiritual y física.

También recomendaba darle leche de pecho o materna al niño hasta la edad de un año, porque era el mejor alimento para el recién nacido; a través de ella la madre le aporta defensas al niño para protegerlo de muchas enfermedades. Durante la lactancia la mamá le estaba brindando amor, caricias y confianza al niño pues era su alimento para el espíritu.

Si la madre no era buena lechera, la partera reconocía remedios que ofrece la tierra para la producción de suficiente leche ya que de la leche dependía la tranquilidad y la buena alimentación.

Para los cuidados de los primeros meses de la vida del niño o niña se les daba bebidas de diferentes plantas para curarlo y prevenirlo de las enfermedades para cuando sea grande no sufriera de dolor de estómago y otras enfermedades que atacan a los niños.

A los niños recién nacidos se les enchumba para que no se caigan y no se tropiecen. Esta práctica se hace con el chumbe ya que este transmite energía y fuerza esto también hará que el nuevo ser sea fuerte en la vida. Si esta práctica no se hace es posible que el niño o la niña crezca muy débil y se lastime muy fácil. Además, si se enchumba él bebe va estar ahí protegido del arco pues el chumbe también espanta las malas energías que hay.

El nuevo ser iba creciendo acompañado de prácticas que ayudaran a marcar su camino, fuetear o sobar las rodillas con las patas del venado ayudaría para la agilidad. 
No podía comer algunas partes de la gallina porque en su crecimiento podría ver visiones y se ira muy rápido de la casa.

De igual manera, para que las niñas sean buenas constructoras de jigras se les hacía cortar las uñas de una persona mayor y trabajadora. Lo mismo pasaba con los niños cuando se quería que fueran buenos trabajadores de la tierra, para ello se debía despertar ese don haciendo remedios con uñas y carne de armadillo ${ }^{5}$ también se podía hacer cortar las uñas de una persona trabajadora, preferiblemente anciana.

Estos extraordinarios saberes que ofrece la Madre Tierra a la partera y al kiwe thë juegan un papel importante en cada ciclo de la vida del ser Nasa.

\section{Lista de referencias}

Asociación de Cabildos del Norte del Cauca- ACIN (2011). Sembrando semillas: "indígenas embazadas de naturaleza".

Yatacue, M. y Vitonas, C. (2012). PEES KUPX FXI' ZENXI “La Metamorfosis de la Vida”.

Asociación de Cabildos del Norte del Cauca- ACIN. (2015). Seguimos en minga por la Libertad de la Madre Tierra. Tejido de educación.

Asociación de Cabildos del Norte del Cauca- Cxab wala kiwe- ACIN- (2006). Hilar y Unir.

Asociación de Cabildos del Norte del Cauca- Cxab wala kiwe- ACIN (2013). Tulpa: La mujer, la familia y el territorio. Tejiendo propuestas desde y para las mujeres nasa.

5 El armadillo es un animal terrestre, con sus uñas construye su casa y su camino, es un animal muy trabajador. 